\title{
Quality of higher education in Kenya: addressing the conundrum
}

\author{
Tristan McCowan (University College London) \\ Published in International Journal of Educational Development (2018), 60, 128-137.
}

\begin{abstract}
Despite the consensus amongst all stakeholders of the critical need for action in the higher education sector in Kenya, national and institutional drives for quality have had limited impact. This study aims to assess the barriers to enhancing quality in Kenyan higher education, drawing on interviews, observations and documentary analysis as part of a three year study. Three types of barrier are identified in the data: resources (staffing and infrastructure), governance (organisational structures and stakeholder participation) and pedagogical culture (social hierarchies and approaches to teaching, curriculum and assessment). On the basis of these findings, it is argued that a threepronged' response is needed: reforms in policy and practice must address simultaneously the material conditions of universities, the forms of institutional organisation, and the cultural relations of teaching and learning.
\end{abstract}

\section{Introduction}

In higher education (HE), as previously seen at primary and secondary levels, there has been a shift of concern from 'quantity' to 'quality'. Since the Second World War, countries at all stages of development focused on expanding their higher education systems to ensure access beyond the traditional elites (Trow 2006). While there is still considerable unmet demand, and significant inequities, the expansion has been remarkably successful, with the proportion of the global cohort moving on to some form of tertiary education now 33\%, increasing from just 19\% in the year 2000 (UIS 2016).

A number of factors have spurred on this rapid expansion. First, governments have been responding to pressure of popular demand for higher education places, particularly in light of increasing secondary completion rates, and family desires for upward mobility (Marginson 2016). Second, drives for national economic competitiveness in the context of the knowledge economy have led to an increasing value placed on higher education, and the need to develop high-level skills in particular areas (Bloom et al. 2006). Third, liberalisation of the private sector - particularly the for-profit segment - has led to accelerated growth through the attractiveness of the market to business investors (Kinser et al. 2010).

However, there are now widespread concerns that this rapid expansion has led to a degradation of quality, particularly in the lower-income countries of Africa, Asia and Latin America. The predicament has manifested itself variously in poor physical infrastructure, overcrowded classrooms, irrelevant curricula, academic staff without the required qualifications, or moonlighting in multiple institutions (Altbach et al. 2009; Salmi 1992; Tetty \& PHEA 2009; Tilak 2013). These problems in delivery have resulted in widespread 
dissatisfaction with the 'product' of higher education - the graduates who emerge into society and the labour market (Agarwal 2009; Dabalen et al. 2000; Oketch 2016; Pitan \& Adedeji 2012; McCowan et al. 2017).

The higher education sector has struggled particularly in these lower-income countries, on account of the more pressing concerns of resourcing universal primary - and subsequently secondary - schools. Annual expenditure per higher education student in Africa decreased from US $\$ 2900$ per year in 1990 to US $\$ 2000$ in 2006 (World Bank 2010). Nevertheless, a rising awareness of the importance of higher education in achieving the new sustainable development goals has placed the sector back on the agenda (Boni, Lopez-Fogues \& Walker 2016; McCowan 2016a; Unterhalter, Vaughan \& Smail 2013). Strong higher education systems are recognised as being important in forming professionals to staff essential public services, to foster innovation and to develop locally generated solutions to development challenges. Clearly, quality in higher education is not an 'added bonus' in relation to these aims: unless the conditions are in place for meaningful learning for higher education students, then the whole rationale for expanding the system in the first place is undermined.

Kenya is a critical case in relation to the challenge of ensuring quality of higher education. After very late development of the sector - as late as the early 1980s the University of Nairobi was the only institution in the country - there has been an extremely rapid expansion, with overall enrolments doubling in just three years: from 218,628 in 201112 to 443,783 in 2014-15, and increasing again to 564,507 in 2016-17 (Republic of Kenya $2015 ; 2017)$. However, the negative impact of the expansion on quality is recognised by all stakeholders and supported by existing research (e.g. Chege 2015; Oketch 2003; Owuor 2012; Sifuna 1998; 2010). A study by the Inter-University Council of East Africa (2014) found that $49 \%$ of graduates are inadequately prepared for work in their areas of study.

At the same time, the country is placing significant emphasis on the role of higher education in national development, as evidenced by the Vision 2030 document, which places technological innovation and high-level skills centre stage (Chege 2015; Republic of Kenya 2007). The Commission for University Education (CUE) has implemented a range of measures to ensure quality assurance processes are in place at every higher education institution. In addition, there are a number of institutional and local level initiatives to enhance teaching and learning quality, including the setting up of centres of excellence, some in partnership with overseas institutions. Yet despite the strong intent on the part of all stakeholders to improve the quality of HE, there are few signs that this is taking place. The question then arises: given the consensus of all stakeholders, why is the quality of higher education in Kenya not being maintained and enhanced? What are the barriers to upholding quality?

This article presents an analysis of this intractable problem. The aim here is not to outline the problems of quality of Kenyan higher education - there are already multiple sources and perspectives on this issue - but to identify and understand the blockages to its improvement. This task requires a broad perspective, assessing national level dynamics, as well as institutional level ones, and taking into account economic, political and cultural dimensions. This study forms part of a broader three-year research project focusing on higher education, employability and development in four countries in Sub-Saharan 
Africa. This part of the study provides a qualitative analysis, drawing on 16 key informant interviews with policymakers, directors of quality assurance, representatives of teaching and learning units and lecturers, as well as field visits, observations of classes and publicly available documentary and statistical sources. The data was collected in a range of public and private universities in Kenya between 2013 and 2015, with the interviews being fully transcribed and analysed using a thematic approach. For ethical reasons, the names of respondents have not been listed; institutions also remain anonymous within the interview data collected, but are named when referred to in publicly available sources. While there are various types of higher education institution in the country including technical and vocational colleges, constituent colleges and specialist institutes - this study will focus primarily on institutions of university status. In addition, the focus here will primarily be on face-to-face courses, rather than distance or virtual provision.

After a review of the evidence on issues of quality, the study focuses on the factors underpinning the challenges, identifying three key forms of barrier: resources, governance and pedagogical culture. Finally, implications are drawn out from the analysis of underpinning factors for the development of national and institutional level policies, and there is also consideration of a range of innovations and new initiatives, and their prospects for success.

\section{Quality in higher education}

It is recognised that there is considerable debate and disagreement as to what constitutes quality in higher education (Cheng \& Tam 1997; Harvey \& Green 1993; Tam 2001). These are not semantic niceties, but touch on fundamental divides of educational vision: as Harvey and Green (1993: 10) state: "This is not a different perspective on the same thing but different perspectives on different things with the same label". While the purpose of this article is not to cover these debates in full, nor to put forward an original conception of quality, it is important to make a brief statement of the way the concept is being utilised.

Quality in higher education can refer to any of the diverse functions of the university, including its research and community engagement activities. While all of these aspects are pertinent, this article will only focus on teaching and learning. The learning environment in the university is seen to comprise not only formal taught courses, but also extracurricular learning activities on campus and beyond, as well as the resources available in institutions for autonomous study, including libraries and information and communications technology (ICT).

In terms of Harvey and Green's (1993) influential taxonomy of conceptualisations of quality in higher education (exception, perfection, fitness for purpose, value for money and transformative), the perspective underpinning this article is closest to the last of these, 'transformation': i.e. that the ultimate gauge of quality is positive change within the students themselves, rather than, say, conformity to product specification, excellence as exclusivity or value for money. This article assumes that there are two forms of transformative learning that should be enabled in universities: 
1. In-depth knowledge, skill and understanding within a specific disciplinary or professional area

2. Broder personal, intellectual, civic and cultural development

To some extent, the learning in area 1 takes place through the formal taught component of a degree, and the latter (2) through co-curricular experiences, service learning and human interactions on campus. However, this is not exclusively so, with all aspects of the institution contributing to both forms of learning, and with significant interaction between the two. Quality of higher education then is the existence of the conditions within universities that foster the achievement of these two forms of learning.

Quality is constituted by elements of inputs, processes and outcomes - as outlined in the proposals put forward in UNICEF (2000) and UNESCO (2004). Attention must be paid, therefore, to the initial infrastructure and personnel provided by higher education institutions - the number and qualification levels of academic staff, the facilities and so forth - the experiences of the students within the university, as well as the learning that they come out with ${ }^{1}$. In the case of Kenyan higher education, there is a lack of rigorous research relating to these three dimensions: for example, there are few adequate gauges of learning outcomes beyond the completion of the 'degree' qualification - for the most part an imprecise gauge. Nevertheless, as will be discussed further in the section that follows, when the numerous sources of information are pieced together there is compelling evidence for the problems of quality.

Having said this, it is important to avoid stereotyping and homogenising. Challenges of quality in Kenya are of course not uniform across the system: in many cases lecturers and departments are beating the odds to provide a rich and inspiring learning environment for their students (see AFELT 2017). The issue is that the system as a whole as it currently stands is not conducive to a quality learning environment for all, and in many cases the excellent practice of individual lecturers and institutions occurs in spite of, rather than because of, the structural conditions of the higher education sector.

This point leads us also to consider the question of equity. As is often the case in educational matters, it is hard to disentangle questions of quality from those of equality. The question arises of quality for whom: most contemporary education systems display markedly stratified opportunities, with high quality learning experiences to a large extent restricted to the more privileged (James \& Holsinger 2009; McCowan 2016b). In the Kenyan context there are certainly disparities between the most prestigious public and private institutions (guarded by competitive exams and high fees) and the rest - although, as explored by some commentators in the section that follows, prestigious universities also face significant quality challenges. Even within particular institutions, gender, social class, regional background and other factors play a part in diminishing the quality of students' experiences (as shown in detail in Morley and Lugg's (2009) research on higher education in Tanzania and Ghana).

\footnotetext{
${ }^{1}$ The UNESCO framework also includes the preparedness of learners entering the educational institution as one of the dimensions of quality: this particular element will not be covered in this article, however, and the focus will be only on the provision made by the university itself.
} 


\section{Higher education in Kenya}

The gross enrolment ratio in higher education in Kenya is measured at a mere $4 \%$ in official international figures (UIS 2016) ${ }^{2}$ - although the real figure is likely to be significantly higher than this, given the dramatic expansion in the period since 2009, the year for which the latest figures are available. While it is still very much an elite system, there has been extraordinary growth, with totals now of 35 public and 36 private institutions (CUE 2017) ${ }^{3}$. However, this expansion has come in the context of a squeeze on public investment, with HE funding as a percentage of GDP decreasing from $0.94 \%$ to $0.74 \%$ between the periods 1996-2000 and 2001-2005 (Wangenge-Ouma 2008). Recurrent expenditure on universities decreased by 18\% between 2012-13 and 2015-16, in spite of the rapid increase in student numbers - although it did recover substantially in 2016-17 (Republic of Kenya 2017).

After the independence of the University of Nairobi in 1970 from previous links to the University of East Africa and University of London, it was not until 1984 that a second institution, Moi University, was created. There has been a gradual expansion in the number of public institutions since that date, with a considerable acceleration in recent years due to the conversion of a large number of middle level technical colleges to university status. There were 14 new public universities created in 2013 alone. There will be even greater expansion with the 2014 amendment to the Universities Act requiring the provision of university education in each of the newly designated counties (Oanda \& Sifuna 2016). However, the majority of the growth in student numbers in the public sector can be attributed to the 'parallel stream', a policy common to East African countries and emerging originally from Makerere University in Uganda (Court 1999). Historically, entrance to public institutions had been controlled by highly competitive admission exams, selecting the highest performing secondary leavers and providing them with generous scholarships including accommodation. Liberalisation of the sector in the 1990s allowed universities to diversify their funding streams, and the major institutions took advantage of the opportunity to admit fee-paying students. Alongside the quota of government funded students, these universities now admit a large proportion of 'parallel programme' or Module II students, who are often in full-time employment and study in evening or weekend courses. These fee-paying students constitute a significant majority of the total enrolment in the largest and best established public universities (Odhiambo 2011).

While in the end it has been the public sector in which the rapid increase has taken place, initially it was the private sector that was touted as the key location for growth (Oanda, Chege \& Wesonga 2008). The first private institution - United States International University - dates from as early as 1970, but the real expansion of the sector took place from the 1990s, after which a number of mainly faith-based institutions were established. Most of these institutions are small in size, and cater primarily to students from higher socio-economic groups who are unable to obtain the grades to enter the elite public institutions. While now comprising approximately $18 \%$ of total enrolments (Republic of Kenya 2015), the private sector has not acted as a major demand absorbing segment, on

\footnotetext{
${ }^{2}$ Gross enrolment ratio

${ }^{3}$ Of the public institutions there are 30 universities and 5 constituent colleges; of the private institutions, there are 18 chartered universities, five constituent colleges and 13 institutions with a letter of interim authority.
} 
account of the restricted proportion of the population able to pay the fees, as well as the aforementioned emergence of the 'parallel stream' in public institutions.

The introduction of the dual track in public institutions has significant implications for equity (as explored in McCowan 2016b). Those students who can afford the fees bypass a highly competitive selection procedure, as students can be admitted to parallel programmes with grades of only $\mathrm{C}+$ in the Kenya Certificate of Secondary Education (Odhiambo 2011). Although deterioration of quality did not begin with the introduction of the parallel stream, researchers (e.g. Wangenge-Ouma 2008; Boit \& Kipkoech 2014) have highlighted the strongly negative impact of this development in public institutions. As stated by Wangenge-Ouma (2008: 464):

Experiential accounts from both lecturers and students painted a picture of despair.... [I]t was not uncommon to find about 800 students squeezed in the lecture halls, with many others following lectures while standing outside the lecture halls or perching on the windows. The beginning and end of lectures were usually marked by chaotic scenes as students jumped in and out from every available opening.

The upsurge in numbers has led to measures such as doing away with tutorials, with a consequent negative effect on opportunities for students to engage in critical reflection and dialogue. It also has had a negative impact on the physical infrastructure:

It is well documented that among other infrastructure and academic problems, windows and doors are falling apart in public universities, residential halls are stinking, there are no subscriptions to journals and no tutorials and that large lecture halls lack efficient microphones. (Odhiambo 2011: 307)

The strain on the public institutions has been exacerbated by the 'double intake' of government-sponsored students in 2011-12 leading to further strains (Gudo, Olel \& Oanda 2011). There have also been significant quality challenges raised by the 'upgrading' of middle level colleges to university status referred to above, and the setting up of many small campuses of established universities in interior towns, often with precarious infrastructure.

There are significant issues of quality, therefore, in public and private sectors. While public universities - particularly the flagship institutions in Nairobi - have the greatest concentration of highly qualified academic staff and research activity, they suffer from significant overcrowding, insufficient numbers of lecturers and degraded facilities. Private universities have lower student to staff ratios, but also have severe challenges, with staff characterised by part-timers with lower qualifications working in multiple institutions. As stated above, while there is far from consensus as to what constitutes quality of higher education, there is a compelling array of evidence in Kenya pointing to quality challenges that would satisfy most conceptualisations, evidence that points to failings in the three key areas of inputs, experiences and outcomes. In terms of the diverse stakeholders, government, university staff, researchers and graduate employers concur that a significant transformation in a system is needed. Interestingly, the one significant group whose dissatisfaction cannot always be clearly heard is the students themselves: 
yet as explored in McCowan et al. (2015), and discussed further below, the lack of a clear critical voice from students owes more to the disempowerment of the constituency than to their contentment with the system.

There are a range of policies underway to support quality of higher education in Kenya. Oversight of the sector is with the Commission for University Education (created in 2012 to replace the previous Commission for Higher Education), whose main responsibility is for accreditation of institutions, recognition of qualifications and quality assurance. While historically the Commission has used its regulatory function mainly in relation to private institutions, its actions are increasingly relevant for the public sector (Otieno 2010). After reforms in 2003 - before which date the President of the Republic was Chancellor of every university - public universities have autonomy from the state, but since the Universities Act in 2012 are required to adhere to the regulations of CUE. Current actions taken by CUE to enhance quality of higher education include requirements for institutional quality assurance, rolling out of course evaluation procedures and changes to promotion criteria. The Inter-University Council for East Africa also has an important role in quality assurance, and has run a capacity building programme (with the German agencies DAAD and HRK) to develop institution level practice. The East African Quality Assurance Network (EAQAN) also has a range of activities in this area (Brewis \& McCowan 2016). However, as will be discussed in greater detail below, while these initiatives have brought some important changes, they have not as yet ensured the enhancement of quality across the system. The remainder of this article therefore focuses on understanding the root causes of the problems of teaching and learning quality in Kenyan higher education.

\section{Barriers to quality}

Analysis of respondents' views, documentary sources and secondary literature points to a large range of barriers to achieving quality in Kenyan universities. As outlined above, these barriers can be grouped into three categories: those relating to resource constraints and lack of investment in universities; those relating to how the system and the individual institutions are run, the deployment of academic staff and their career incentives; and lastly dominant approaches to teaching and learning, and forms of assessment and the relations and interactions between lecturers and students. All of these in turn, are underpinned by deeper cultural, political and economic forces in society, as indicated by the graphic below: 


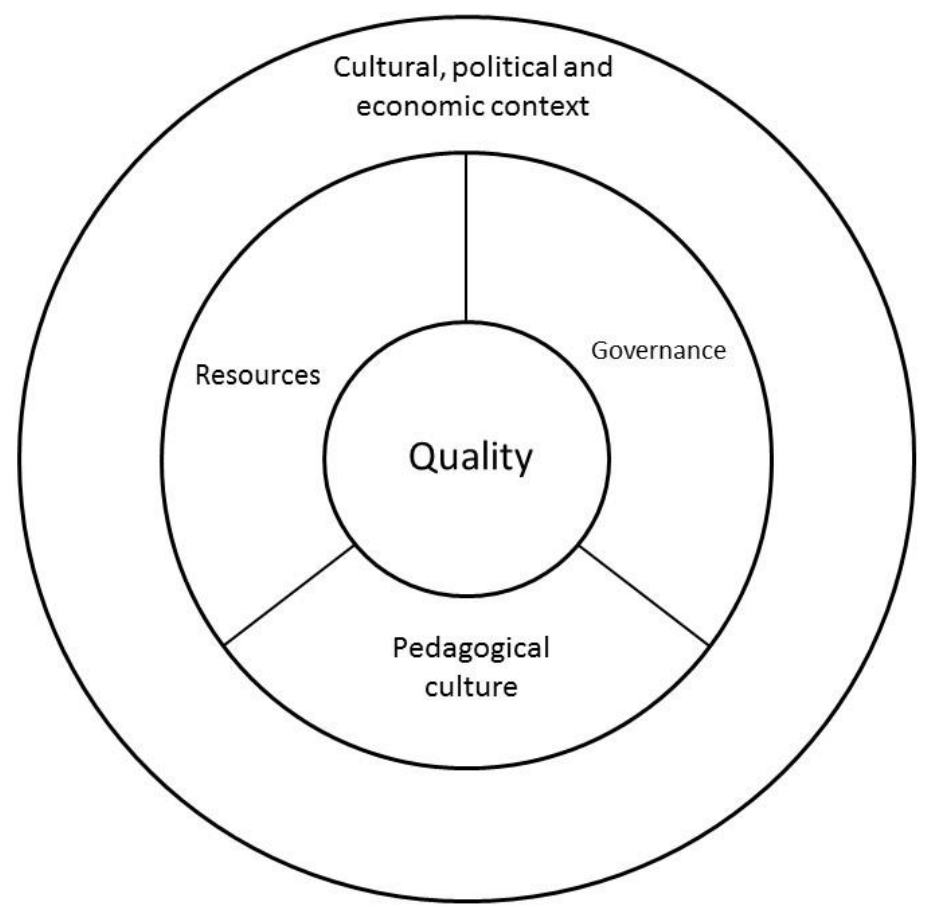

[Source: Author]

This analysis will focus primarily on the intermediary ring, that of the immediate factors affecting quality, as this is the level at which interventions in the short term can most meaningfully be made. Nevertheless, while this is the explicit focus of the article, it must be recalled, as with all questions of policy and practice in the social sphere, that many of these issues are rooted in deeper historical and contemporary questions such as colonialism, neo-colonialism, dominant economic and political structures, epistemologies and cultural norms.

Each of the three categories of resources, governance and curriculum and pedagogy have a series of sub-factors that will be outlined below. These categories will be analysed drawing specifically on the interview data collected with lecturers and senior managers of public and private institutions, as well as national level policymakers.

\subsection{Resources}

The financial allocation made to universities is essential so as to ensure sufficient staffing and physical resources. Considerations of resources include the total amount available nationally for higher education, as well as effective allocation and equitable distribution between and within institutions. Perception of lack of resources may be common to all universities across the world, and desire for additional resources may indeed be limitless. However, in Kenya resource levels have not reached even a minimum acceptable level. As outlined in the previous section, problems have been caused first and foremost by the 
rapid increase in enrolments without corresponding investment, leading to a drop in the level of resource per student. The rapid expansion of the parallel stream, as well as the double intake, have exacerbated these problems in public universities. Resourcing issues for the most part are less acute in private institutions, though many of these also suffer from inadequate physical infrastructure and equipment.

\section{$\underline{4.1 .1 \text { Staffing }}$}

The most evident manifestation of poor quality higher education in Kenya is large class sizes. While there is extensive debate in educational research on the effect of class size on student performance, there is little doubt that classes of many hundreds, without appropriate facilities and support activities, makes learning extremely difficult for students (Foley \& Masingila 2014; Allais 2014). Furthermore, for many students in Kenya, large-scale lectures represent the only form of teaching, with few opportunities for tutorials or breakout seminar groups. Very high student lecturer ratios are evident across public institutions in Kenya, with an average of one lecturer for 70 students (Chege 2015). In fact, these figures may even underestimate the ratio, given that public universities are believed to under-report student numbers on account of confidentiality of the exact size of their private student cohort. One respondent spoke of class sizes of 1200 at his institution. Another lecturer reported that his institution had attempted to continue with 'tutorials', in addition to lectures, but that these groups customarily had as many as 200 students.

In part the lack of academic staff is caused by a lack of investment in universities. However, there is also a lack of capacity, with insufficient qualified candidates to fill places (Wangenge-Ouma 2008). Given the low turnover of new PhDs in the country, and the loss of many highly qualified staff through brain drain, it is hard for universities to find adequately qualified applicants when they are looking to recruit (Odhiambo 2013). In addition to unfilled places, this lack of capacity has led to inadequate qualifications of academic staff in some cases, or of staff taking on responsibilities beyond their level of seniority or outside their area of specialisation, taking on extra teaching load for more pay, or assigning teaching assistants to full teaching responsibilities - all of which have a potential negative impact on quality (Gudo et al. 2011; Wangenge-Ouma 2007). Difficulties of recruiting full-time staff - as well as the corresponding expense - have also led a number of institutions to take on high proportions of part-time staff. In one of the prestigious private institutions participating in this study, $80 \%$ of credit hours are taught by part-time staff. Lecturers moving between a number of institutions are seen to have less time and commitment to ensuring the broader development of their students.

The difficulties described here relate mainly to undergraduate teaching, but there are also staff shortages at the postgraduate level: while class sizes are generally much smaller for Masters students, allowing for a greater amount of discussion and debate, there is a critical lack of supervisors in many cases, as well as downgrading of dissertation requirements (Wangenge-Ouma 2007). Strains on administration are also brought about by the lack of non-academic staff in universities.

A further resource issue is the relatively low level of salary paid to staff. As is the case with teachers at school level, low salary has a number of negative effects on quality of 
education. First, it reduces the attractiveness of the profession, thereby making it harder to recruit high performing graduates. Second, it has a negative effect on lecturers' sense of recognition from their institutions and society, leading to a decrease in motivation. Third, it increases likelihood of lecturers seeking additional sources of income. This final point was highlighted by a number of respondents: 'moonlighting' of lecturers in other institutions is seen to be very common, leading to absenteeism, cancelled classes, burnout of lecturers and lack of time to devote to students. As an academic developer in a private institution stated:

[I]f you ask me, that interferes with the quality of teaching that you engage in because I can't be in Nairobi today, Mombasa tomorrow, Nakuru....when do I have time to sit and reflect and think through my teaching?

\section{$\underline{4.1 .2}$ Physical resources}

Quality of higher education is also dependent on adequate physical environment and specific teaching resources. Universities report minimal equipment available in classrooms, and lack the specialised equipment needed for particular fields of study: in particular, laboratories for science subjects, fisheries for aquaculture and so forth. Library and ICT resources are also inadequate for students to partake in individual study outside class time. The combination of lack of human resources and teaching resources has a magnifying effect, as effective teaching of large classes to a large extent depends on audio-visual and other equipment in classrooms, and other forms of virtual learning and library facility to ensure individual and group learning outside of formal classes (Allais 2014). Only a handful of elite private universities in the capital are seen to have adequate facilities and equipment, with projectors in each classroom, broadband access for students and classrooms with an adequate layout to allow for interaction and discussion.

In some cases, greater financial autonomy has allowed institutions to enhance their infrastructure: a prominent example here is Kenyatta University, in which international collaborations have enabled the construction of a number of new university buildings, most notably the Campanile and the escalator-adorned Post-Modern Library. Nevertheless, respondents were sceptical about whether these eye-catching displays of institutional development had actually lead to any improvements in the infrastructure for learning.

\subsection{Governance}

Resources, however, can only act to boost quality if they are allocated effectively and efficiently. Conversely, even in the context of resource constraints, respondents considered that the higher education system could be managed in ways that enhanced quality to a greater extent. These points relate in part to national level governance, as well as the management of individual institutions, and broader questions of the participation of key stakeholders. 


\section{$\underline{4.2 .1}$ Marketisation}

The broader backdrop of marketisation and commercialisation cannot be ignored in relation to the question of quality. While liberalisation of the private sector and autonomy of public institutions to generate income has rapidly increased the number of places, they have not ensured maintenance of an adequate quality of provision. Crudely put, competition between providers has not 'weeded out' poor quality products, as an HE degree still has considerable attractions (and in many cases real value), even if the diploma was gained with little meaningful learning (McCowan 2016b).

A further point is that instead of having a well thought out national plan for student numbers and distribution across disciplinary areas, unbridled commercialisation has led to institutions rushing to offer courses in any area in which there is a perceived market for students, regardless of the capacity of the institution to provide a quality offering in that area, or of the employment opportunities for students subsequently. 'Duplication' of courses has therefore become a key concern for many commentators (Oanda \& Sifuna 2016).

The financial incentives to recruit ever greater numbers of students is also encouraging institutions to admit students without the requisite level of preparation. As one lecturer in a private university stated: "The cut-off point is a $\mathrm{C}$ with a $\mathrm{C}+$ in Maths and English but some universities flout the rule as they need students." As discussed above in relation to physical resources, marketisation of admissions and entrepreneurial activities of universities have allowed for the entry of new funds, although not always leading to improvements in research and teaching quality.

\subsubsection{Quality assurance and quality enhancement}

As outlined above, there have been a range of measures put in place to ensure quality in the Kenyan higher education system, and relevant bodies have been established at institutional, national and regional levels. However, action to date has been largely in the realm of 'quality assurance' as opposed to 'quality enhancement' (Brewis \& McCowan 2016; Odhiambo 2014), focusing on course validation, accreditation and audit procedures rather than in supporting lecturers in developing their teaching practice and students in enhancing their learning.

Universities are required by CUE to have a director of quality assurance and procedures in relation to programme delivery and evaluation, yet the Commission was seen by respondents to lack expertise on issues of teaching and learning, and also to place a strong emphasis on traditional exams, resisting the alternative forms of assessment proposed by some universities. One academic developer at a private university interpreted this tendency towards inertia as being a result of the fact that those in power had succeeded in the system:

And the people who are running, you know, the ministry of education, the people who are running CUE, these are the people that excelled in that system. They were the crème de la crème, they were the best of the best in that system. And it's really hard for them to look back on it and 
say, "You know, that system needs to change," because it worked for them. You know, they got the big titles and the big offices and the big leather desk and so forth. So it's hard for them to see that there's a real problem with it.

Furthermore, respondents pointed to a mismatch between the official requirements and the reality in institutions. CUE (2014), for example, has guidelines on the maximum student-lecturer ratio (ranging between 1:7 for medical sciences and 1:18 for social sciences), but according to the respondents, no public university in Kenya is complying with them.

Nevertheless, a number of universities have recently set up teaching and learning support units or Centres for Excellence in Teaching and Learning, for example Kenyatta University, University of Nairobi, Moi University and Daystar University. These units provide professional development workshops for staff, advice on pedagogy and assessment, peer observations and sometimes other functions such as coordinating student course evaluations. Furthermore, a number of universities are developing formal qualifications in higher education teaching and learning: for example, Strathmore has a new certificate for education in academic practice, and Daystar is developing a postgraduate diploma.

These are promising developments, and have allowed for innovative teaching practices to blossom at the local level. Nevertheless, across the system there is still a severe lack of teaching and learning support. With the exception of those universities that have dedicated teaching and learning centres, most institutions offer little more than an initial induction day. Even in the cases of those universities with centres, there are a range of constraints on their effectiveness, primarily due to lack of staff members, inadequate preparation of the staff that are in place and lack of funding. With few exceptions, those involved in teaching and learning support in universities expressed dissatisfaction with the support received from their own senior management. Some organisational difficulties are presented by the fact that learning and teaching units sit outside of faculties, since lines of 'command' generally function through the Deans. Successful examples cited were those in which teaching and learning units had worked closely with Deans.

\section{$\underline{4.2 .3 \text { Corruption }}$}

An investigative report published in the Daily Nation in February $2015^{4}$ showed the widespread corruption in the higher education sector and the selling of degrees in certain institutions, most notably the Nairobi Aviation College. According to the exposé, "A lecturer at the college told us that he had helped thousands of students to acquire certificates without their setting foot in class". While pointing the finger at corruption can sometimes serve to deflect attention from the deeper roots of problems of political and economic organisation, it is important to acknowledge its relevance for the issue of quality of higher education in Kenya. CUE has become more active in this regard in recent

\footnotetext{
${ }^{4}$ Okari, D. (2015) How universities and colleges sell diplomas and clean up degrees. Daily Nation, $1^{\text {st }}$ February.
} 
years, for example succeeding in shutting down 'Barack Obama University' in 2015, which was attempting to sell its courses despite not having been registered.

Two forms of corruption were pointed to as challenges by the respondents: first, the existence of diploma mills and bogus degrees of the type outlined above; and second, and most commonly, malpractice in relation to assessments. In some cases there was a lack of confidence in assessment procedures, or outright exam malpractice, involving manipulation of grades. For example, one observation documented a lecturer selling packs of course notes to students at a profit, effectively obliging the students to purchase them if they wanted to pass the exam.

A final point relates to the issue of political interference in universities. While this has historically been a major bone of contention, particularly in the period before 2002 in which institutional autonomy was severely curtailed (Odhiambo 2011; Sifuna 1998), it was not, however, pointed to as a significant concern by respondents interviewed.

\subsubsection{Engaging academic staff}

Next, there were a range of factors related to the status, working conditions, management and support of academic staff. To a large extent, lecturers have little encouragement, incentives or time availability for developing their teaching practice. First, promotion requirements are primarily oriented around research, with little recognition of teaching (for example one of the participating universities attributed $20 \%$ of the evaluation to this dimension); Kenya is certainly not unusual in this globally, in giving research funding and publications the greatest weight in promotions. The establishment of new qualifications for teaching and learning are going some way to addressing this issue, as is the increasing attention given to course evaluations, but stronger links with enhancing teaching quality are needed.

Workload is therefore a significant issue, exacerbated by the question of low salaries and moonlighting discussed above, as well as increasing enrolments (Calvert \& MuchiraTirima 2013; Wangenge-Ouma 2008). Consequently, there is little time available for academic staff to attend professional development activities. Arasa and Calvert (2013) in their study found that lecturers did in fact value teaching highly, but were prevented from dedicating sufficient time to it not by the competing demands of research, but by extra paid teaching work and non-university commitments. Engagement is seen to be undermined by all of these factors:

$[\mathrm{H}]$ ow do you feel about yourself when you've got two matatus ${ }^{5}$ into work because you're saving on petrol because you feel you're underrewarded and you're not being paid enough. You may well be moonlighting or you may be doing extra courses instead of doing some of your research study... So it's...the actual lives of the lecturers I don't see being terribly enjoyable. And a lot of them have got their own farms or they've got their building projects or they've got their businesses.... They're earning money in other ways to make do. So, if you take all of

\footnotetext{
${ }^{5}$ Minibuses commonly used in Kenya for public transport.
} 
those together, and it's a wonder that some of them go in as bright-eyed and bushy-tailed as they do. (International partner)

A further issue is around the lack of meaningful engagement of 'rank and file' academics in decision-making, leading to a lack of ownership. As stated by the director of quality assurance of a private institution:

We have also been dealing with a lot of apathy among faculty, and the apathy is a result of, among many other things, their perception of governance, the university governance. So a lot of them have felt like they're not quite...would I say involved, or considered, or appreciated, that kind of thing. So it has been a question of them versus us, you know, the administration and us.

The feeling of exclusion from decision-making, combined with the sense of not being valued, leads to a reluctance to engage in professional development activities unless made obligatory, and adherence to the minimum acceptable in terms of teaching responsibilities.

\section{$\underline{4.2 .5 \text { Empowering students }}$}

One of the major blockages for improving quality, therefore, is responsiveness of institutions to their stakeholders. In addition to lecturers, another key constituency in this regard is the students themselves. As shown in previous research (McCowan et al. 2015), students are unwilling to complain publicly about their institutions, even when they have a range of serious concerns. Despite the formal representation on university boards and committees, they lack channels to express their views and have them listen to seriously - a fact which at times has led to dissatisfaction 'boiling over' into violent unrest (Amutabi 2002).

Course evaluations are in fact used by a majority of institutions. These provide an opportunity for students to comment on their experience in a particular module, and provide feedback on the quality of teaching and curriculum. Respondents reported that information from the evaluations was collated and fed back to departments and lecturers, and led to additional teaching support and development of new strategies. As such they are an important mechanism in ensuring quality. However, there are some limitations on the effectiveness of these evaluations. First, there are question marks about the authenticity of the student views expressed, given the deeper disempowerment of students alluded to above. In some cases students were not certain of the anonymity of the feedback. In addition, students' primary interest is in successful completion of the course, so they will inevitably be swayed as much by the potential knock-on effect on their own grade as they will by dispassionate interest in improving the course for future cohort of students. 'Easy' classes with guaranteed grades may therefore be rewarded by positive evaluations, while more challenging pedagogical experiences with much richer learning outcomes may not. (Mid-term evaluations have been proposed to address this issue). Finally, there were instances reported of lecturers removing negative feedback forms before submitting to the office. These are not challenges confined to Kenya by any 
means, and are characteristic of all formal education systems which combine competitive marking systems with the aim to provide meaningful learning experiences for all.

There is a broader challenge - possibly a characteristic of all higher education systems to some extent - of a certain 'complicity' between students and their institutions. The role of the degree certificate as recognition of one's learning - and the dependence of the prestige of that degree on the 'brand' of the institution in question - mean that students have an interest in defending the quality of their institution, even when they do not fuly believe in it. An associated, and perhaps more serious point, relates to the potential disjuncture between actual learning and the awarding of the degree. If students are confident that they will leave the university with the required qualification - and the receiving of that qualification is more important even than learning anything of use - then they have little incentive to complain about lecturer absenteeism, overcrowded classrooms and lack of learning resources. There is even less likelihood of them speaking out about these problems given the direct threats of withholding the awarding of the degree made to some student activists across the continent.

\subsection{Pedagogical culture}

The third of the three dimensions relates to the practices of teaching and learning themselves, the broader curricular offering, and importantly the set of collective beliefs and relationships that support those practices. As explored by Schendel (2016), it is not enough for academic departments to adopt progressive pedagogical forms, without a deeper process of transformation of lecturers' understandings and cultures of practice. As stated by a director of quality assurance from a public university:

[A]ctually culture is a major problem when you are trying to bring change. Traditionally higher education was something that people were seeking and the lecturers taught you what they wanted to teach you.... [T] his new situation means that it requires a different culture.... [N]ow you have to teach the students and give them the skills they need.

\subsubsection{Curricular offering}

A full analysis of the curriculum in Kenyan universities is not possible in the context of this article, but some brief points will be made. There are widespread concerns in the national media about problems of employability and 'half-baked graduates' (Republic of Kenya 2013; IUCEA 2014), and to some extent at least these problems are attributed to the irrelevance of curricula, to the courses being out of touch with advances in industry and changes in the employment market, as well as dislocation of theoretical knowledge from application in real-life situations. In some cases professional bodies have refused to recognise degrees ${ }^{6}$. In relation to the integration with the workplace and application of knowledge, differences were observed between disciplinary areas. Health-related courses have been active in introducing problem-based learning (for example in Moi

\footnotetext{
${ }^{6}$ Wanzala, O. (2015) Suspension of courses puts varsity regulator on the spot. Daily Nation, $3^{\text {rd }}$ October.
} 
University), and business studies makes extensive use of cases. However, even some highly applied courses - such as project management or agriculture - can lack a practical element, in many cases exacerbated by lack of resources.

Two specific trends in relation to distribution of courses were identified by respondents. First, there is what has been called 'programmatic isomorphism' (Wangenge-Ouma 2007), related to the globally identified trend of 'mission creep'. On account of desire for prestige and emulation - and in some cases market benefit - the new entrants to the higher education sector end up duplicating the kinds of courses available at the better established institutions. This dynamic prevents positive forms of diversification of the sector, with institutions having distinctive ethoses and course offerings, resulting particularly in technical institutions starting to resemble academic ones. Furthermore, the new courses offered have for the most part been in the applied social sciences, leading to a shortfall in the areas of natural science and engineering, which are more demanding in terms of infrastructure (Oanda \& Jowi 2012).

A second - and apparently contradictory - tendency is that of 'course splintering'. In this case, in order to gain commercial benefit, universities will divide a single area into a number of more specific courses, thereby making them too narrow for use in later employment, or at least providing little added value. One public institution provides separate undergraduate degrees in 'Hospitality Management', 'Tourism Management', 'Leisure and Recreation Management' and 'Philosophy in Hospitality and Tourism Management', with further new courses planned in 'Catering and Institutions Management', 'Restaurant Management', 'Food and Beverage Management' and 'Meetings and Events Management'.

A final point relating to the curriculum concerns the lack of a broader campus (or beyond campus) experience of learning. With the exception of the elite Nairobi-based universities, there is a lack of extra-curricular provision - in the form of sports, artistic and creative pursuits - as well as support services such as careers and counselling. Given the centrality of these activities in enhancing students' employability, and broader civic development, this is a worrying state of affairs, and is particularly critical for those lowerincome students who will often not have access to these activities outside of the university.

\subsubsection{Teaching methods and pedagogical relations}

Without doubt, it is dangerous to peddle stereotypes about pedagogy in African universities, and many lecturers use progressive methods to ensure a rich and engaging learning environment for students. Nevertheless, it is undeniable that in many institutions transmission pedagogy does dominate, and the 'yellow notes' phenomenon of lecturers delivering lectures for years (if not decades) based on the same outdated content - is a reality in many cases. As has been seen, the causes for adherence to transmission pedagogy are complex, and relate to issues of a macro-political nature, involving allocation of resources and governance, as much as they do to micro level social and cultural interactions. As stated by the head of the teaching and learning support unit at a public university: 
Because if ever I ask a question, the student is sitting very far. They don't have a microphone. I can't even write on the white board. So you just go in and you are just talking.... Sometimes maybe the rooms are not available, lecture rooms... if you have three hundred students in a room of one-fifty, some of them will be standing at the windows also.

An international partner confirmed this view:

[W] hen the students are crammed in...it makes it very, very hard. And, of course, the simple way of doing things is transmission-mode teaching: the definition of which is the most economical way of getting the lecturers' notes into the students' notes without passing through the brain of either party.

Large classes are seen to make building personal relationships impossible. However, resources are not the only determinant of pedagogy. Teaching practices are also dependent on the availability and type of training and staff development (discussed above) and dominant pedagogical and cultural views and trends. As seen in relation to school teachers (e.g. Brinkmann 2015), adoption of learner-centred pedagogies is highly difficult when teachers hold deeper beliefs that run contrary to the underlying principles.

One cultural feature reported as a barrier in transforming pedagogy is deference to authority. The hierarchical nature of Kenyan society - particularly in relation to age, but also to rank seniority - can serve to silence those in more junior positions, and acts against the kind of open dialogical space conducive to development of critical learners. Beyond the classroom, it can also serve to silence committed staff attempting to introduce innovations in teaching and learning. Fears of speaking out relate not only to hierarchies, but also operate horizontally with peers:

And it's possible that you ask questions in class and you end up answering them yourself, because...because of that distance. And even with the students, amongst the students themselves, they tend to have a fear of, you know, looking bad in front of their colleagues and so they won't speak. (Lecturer, private university)

In a similar vein, one of the respondents highlighted fear of peer observation as a barrier to lecturers developing their teaching practice.

While it may be distorting to overstate the association between age and pedagogical style, respondents did observe that older lecturers were more resistant to adopting learner centred pedagogies than younger lecturers. In some cases this was linked to the concrete question of career stage, with more experienced academics having less incentive to attend courses as they did not need them for promotion.

Central to transformation in the above areas of curriculum, pedagogy and assessment is ongoing professional development of teaching staff. While most institutions have induction courses for new staff, and some ongoing training in the area of teaching, respondents highlighted significant needs in this area. Often, even when there is provision, there is low uptake by academic staff: as outlined above, this may be due to 
lack of time, but there is also the question of academic identities. For many academic staff, there is an ingrained sense that their commitment is to excellence in scholarship in their academic discipline rather than to teaching. As stated by the head of teaching and learning at a private university: "the assumption by most is I have the qualification, I have the PhD...so I can teach, I am able to teach. So as soon as there is a problem it is the student, no, it's not me." Another source of resistance was amongst those who already had some background in teaching methods: ironically, lecturers in Education were particularly unwilling to engage in ongoing professional development related to teaching.

A related barrier is the incipient nature of scholarship on teaching and learning in Kenya, and the lack of support for research in this area. As is true many contexts, lecturers rarely have sufficient familiarity with research and concepts in this area, and do not have space to reflect on their own teaching.

Perhaps surprisingly, a number of respondents pointed to resistance from students as a key barrier. For those lecturers who have implemented changes and were encouraging a more participatory dialogical space in their classrooms, students sometimes complained, calling for a return to the comfort of the familiar:

$[\mathrm{M}] \mathrm{y}$ students were getting shocked by my approach...at first they were very resistant.... [T] hey think she's making us do everything, you know? They didn't like it... [T] hey just sit back and they just...they want the notes so that they can cram for the exam. So they start at the end and they want to..."What are you bringing in the exam?" You know, that's what they want to know. (Lecturer, private university)

However, the same respondent highlighted that after a few weeks they became increasingly comfortable with the approach. The indications are that after a short period of resistance, students appreciate a more dialogical and active approach to learning, even if it may require more effort. Overall, resistance amongst faculty was seen to be more of a problem than resistance among students.

\subsubsection{Exam culture}

A key barrier to development of more effective pedagogy highlighted by many of the respondents was the perceived culture of examinations. While exams rarely count for all of the student assessment in university courses - commonly there will be $70 \%$ awarded for exam, and $30 \%$ for continuous assessment - nevertheless, the exam continues to be the 'gold standard' for validating students' knowledge. Attachment to the exam is seen to go right from the top at the level of CUE, down to the faculty and departmental level. This relates to a deeper question of the relation to knowledge:

[T] here's an interesting phenomenon, especially when you're done with primary school and you're moving on to high school, there's a tendency for people to burn their books. You literally just set them on fire because then, you know, that's the end. When you're just about to go to the university you do the same thing.... [I]t really waters down what learning 
is all about, so it stops being lifelong and it begins to become exam-long. As soon as the exam is over, then that's it. (Lecturer, private university)

Respondents pointed not only to the existence of exams, but also to negative practices within exams, in particular marking focused on regurgitation of a number of key points. Assessment, as ever, has a 'backwash' affect, and influencing prior teaching and learning. Dominance of exams as a system of assessment leads to emphasis on memorisation and on faithful reproduction rather than critical reflection and creative engagement.

$[\mathrm{H}]$ ow many of us have heard horror stories, I know it happens in the government universities here, where professor shows up on day one of the class, four hundred/five hundred students in the class, tells them, you know, "Here's the list of books to read, I'll see you at the exam." And that's it! Never another class. And the students go and cram and cram and read and then they take the exam and they pass the course. (Academic developer, private university)

A range of factors relating to pedagogical culture are therefore seen to be influential in facilitating and strengthening quality enhancement. The final section will now distil the key elements from these findings and draw our implications for responses on the part of the government and institutions.

\section{Implications for policy}

Multiple factors have, therefore, been identified as underpinning the challenges that Kenyan universities face in maintaining a high quality of teaching and learning. In the space available in this article it has only been possible to provide a brief outline of each of these broad and complex areas: a full analysis would require focused attention on each of the sub-areas. The main purpose here has been to show the contours of the problem and broad areas in which action is needed. In categorising the factors of resources, governance and pedagogical culture, it is important to emphasise the significant interaction between the three elements. Insufficient resources make it hard to practice pedagogy conducive to deep forms of learning - as has been seen in the literature on the challenges of implementing learner centred pedagogy in schools in low-income countries with very large class sizes (Schweisfurth 2013). Poor governance and low remuneration lead to a lack of trust and motivation on the part of academic staff, which undermine efforts to ensure ongoing professional development and high standards of practice. In some cases, poor quality of provision and ineffective governance may make it harder for universities to attract both public and private funds. Or in a more positive way we can say that these three areas - resources, governance and pedagogical culture - are mutually reinforcing: as one starts to be enhanced it will facilitate improvement of the others.

We, therefore, need a three-pronged approach to address these areas simultaneously. It is not uncommon to hear proposed solutions that focus exclusively on one side of the problem - professional development, say, or recruitment of new lecturers. These will only work if corresponding changes are made in the other areas. Resource constraints cannot be ignored, as ultimately the system can only fully improve with greater investment. The financial challenge of funding higher education is one that must be faced head-on by Kenyan state and society - in conjunction with (and not as a trade-off against) 
funding for primary and secondary education. Yet resources are a necessary but not a sufficient condition for improvement. There are also a range of other changes that must be made. Furthermore, these are changes that can take place at relatively low cost, and in the short term - whereas increased investments may require significant change of political will, or improvement of the national economic situation. For example, a smallscale partnership between York St John's University in the UK and Strathmore University, involving a professional development course for a small number of staff committed to teaching and learning enhancement in institutions in Nairobi, led to observable transformation of practices, as knock-on staff development programmes and enhanced teaching and learning support were rolled out through a 'ripple effect' in the subsequent months and years.

In terms of governance, it is clear that a substantial amount of caution is needed with marketisation of the system. Awareness of resource constraints had instigated the policies of privatisation from the 1990s, leading both to the emergence of a number of private providers and the development of the dual track in public institutions. However, while these responses have ensured the continuing expansion of the system, they have done so at the expense of quality. As discussed above, the disjuncture between degree diplomas and quality learning experiences means that market mechanisms are not enough to ensure consistently high quality across the system. Low quality courses will still attract fee-paying students if the latter are confident they will obtain a qualification of value in the job market. Nevertheless, net gains for society are only obtained through the maintenance of a high quality learning environment, leading to increases in workplace productivity in graduates and other positive contributions to society. State intervention in the system is therefore necessary in order to ensure quality across the system, involving a combination of investment of public resources - so as to fund areas in which there is market failure, and ensure equity; of regulation - including mechanisms conventionally associated with quality assurance, as well as addressing issues such as lack of incentives for individual lecturers to focus on teaching excellence; and of information for prospective students. Furthermore, the student voice needs to be engaged with to a far greater extent, allowing involvement of students in decision-making relating to their learning and ensuring greater accountability of institutions to their interests.

Finally, efforts are needed at the grassroots level to enhance pedagogical culture. Studies such as that of Schendel (2016) show the significant impact that conducive departmental culture can have transforming the rhetoric of learner-centred education into pedagogies that can enhance student learning. Academic staff development is an important part of this process, and there are a number of promising new initiatives in this area. The development of credit-bearing qualifications in teaching and learning in higher education provide a potential solution, by ensuring that incentives are in place and time ring-fenced for lecturers to engage in these activities wholeheartedly. Mentoring and peer observations schemes, as well as changes in promotion criteria, are also important interventions. As with many debates in higher education, it is impossible to divorce them completely from dynamics at the primary and secondary levels. So, habits and expectations among students and lecturers about teaching methods, assessment and interpersonal relations are entrenched by earlier experiences of learning. Addressing these challenges at the higher education level - as is the case with questions of equity of access - involves simultaneous interventions at the lower levels of the system. 
Furthermore, as emphasised above, a number of the challenges in pedagogy are rooted in deeper cultural questions of social hierarchies and relationships to knowledge, and as such will require a long time frame for change to take place.

As seen above, there are a range of innovations and progressive movements in pedagogy already in place, emerging from particular champions within institutions, as well as coordinated institutional efforts. Effective academic staff development programmes (some involving blended learning) have been set up in a range of institutions - including Strathmore, Daystar and Aga Khan, with its Network of Teaching and Learning. Approaches such as problem-based learning and constructive alignment, use of student learning mentors and alternative forms of assessment such as portfolios, have also been incorporated in courses across the country. Nevertheless, even those institutions at the forefront of progressive practice struggle to universalise these reforms. In order to address this challenge, the Association for Faculty Enrichment of Learning and Teaching (AFELT) has been established: this grassroots networking organisation of institutional leads in academic development and quality assurance was founded in 2014 with the mission of advocating teaching and learning enhancement initiatives in the country. It has the potential to bring lasting change in the system through capacity building, ensuring buy-in of academic staff, providing a forum for sharing innovations and bringing tangible changes to teaching and learning practice. These initiatives and innovations need to be nurtured and supported if system-wide changes are to take place and achieve lasting effect.

Kenya - like other contemporary societies - presents an ambitious vision for its own development, with demands made for a creative, tech-savvy and globally connected population to drive forward a prosperous and equitable society. If these critical, creative graduates are to be produced, then there needs to be a 'constructive alignment' (Biggs 1999) of higher education pedagogy in line the vision of society to be attained. This transformation of the higher education system will require coordinated action to address the interlinked barriers that currently hamper the emergence of a rich and conducive learning environment for students.

\section{Acknowledgements}

This study was carried out with funding from the British Council as part of the Universities, Employability and Inclusive Development research project. My thanks go to Rebecca Schendel for her comments on an earlier draft, to Elisa Brewis for her contributions to data collection, to Ibrahim Oanda for his support and insights throughout the project, and to all of the university staff in Kenya who participated in the research. 


\section{References}

Agarwal, P. (2009) Indian Higher Education: Envisioning the Future. New Delhi: Sage Publications.

Allais, S. (2014) A critical perspective on large class teaching: the political economy of massification and the sociology of knowledge. Higher Education, 67 (6), 721-734.

Altbach, P. G., Reisberg, L. and Rumbley, L. E. (2009) Trends in Global Higher Education: Tracking an Academic Revolution. Paris: UNESCO.

Amutabi, M. N. (2002) Crisis and Student Protest in Universities in Kenya: Examining the Role of Students in National Leadership and the Democratisation Process. African Studies Review, 45 (2), 157-78.

Arasa, J. and Calvert, M. (2013) Negotiating Professional Identities in Higher Education in Kenya: dilemmas and priorities of Faculty, Journal of Post-Compulsory Education, 18 (4), 402-414.

Association for Faculty Enrichment in Learning and Teaching (AFELT) (2017) AFELT. Available at: http://www.afelt.org/. Accessed 17/10/17.

Biggs, J. (1999) What the Student Does: teaching for enhanced learning. Higher Education Research \& Development, 18 (1), 57-75.

Bloom, D. Canning, D. and Chan, K. (2006) Higher Education and Economic Development in Africa. Massachusetts: Harvard University.

Boit, J. M. and Kipkoech, L. C. (2014) Effects of democratizations of university education on quality of higher education in Kenya: A case of Moi University. International Journal of Educational Administration and Policy Studies. 6 (1), 5-8.

Boni, A., Lopez-Fogues, A. and Walker, M. (2016) Higher education and the post-2015 agenda: a contribution from the human development approach. Journal of Global Ethics, 12 (1), 17-28.

Brewis, E. and McCowan, T. (2016) Enhancing Teaching in African Higher Education: Perspectives of quality assurance and academic development practitioners in Ghana, Nigeria, Kenya and South Africa. British Council.

Brinkmann, S. (2015) Learner-centred education reforms in India: The missing piece of teachers' beliefs. Policy Futures in Education. 13: 342-359.

Calvert, M. and Muchira-Tirima, K. (2013) Making sense of professionalism and being a professional in a Kenyan higher education context, Journal of Education for Teaching, 39:4, 370-382. 
Chege, M. (2015) Re-inventing Kenya's university: From a “Graduate-mill” to a development-oriented paradigm. International Journal of Educational Development, $44,21-27$.

Cheng, Y. C. and Tam, W. M. (1997) Multi-models of quality in education. Quality Assurance in Education, 5:1, 22-31.

Commission for University Education (2014) Universities Standards and Guidelines, 2014. Available at: http://www.cue.or.ke/images/phocadownload/UNIVERSITIES_STANDARDS_AND _GUIDELINES_June_2014.pdf (accessed 24/5/16)

Commission for University Education (2017) Accredited Universities in Kenya - March 2017. Available at: http://www.cue.or.ke/images/phocadownload/Accreditted_Universities_March_2 017.pdf (accessed 17/10/17)

Court, D. (1999) Financing Higher Education in Africa: Makerere: the Quiet Revolution. Washington DC: The World Bank.

Dabalen, A., Oni, B. and Adekola, O. A. (2000): Labour Market Prospects for University Graduates in Nigeria. The Nigeria University System Innovation Project Study.

Foley, A. R., \& Masingila, J. O. (2014) Building capacity: Challenges and opportunities in large class pedagogy (LCP) in Sub-Saharan Africa. Higher Education, 67(6), 797-808.

Gudo, C. O., Olel, M. A., Oanda, I. O. (2011) University expansion in Kenya and issues of quality education: challenges and opportunities. International Journal of Business \& Social Science, 2 (20), 203-214.

Harvey, L. and Green, D. (1993) Defining quality. Assessment and Evaluation in Higher Education 18, 8-35.

Inter-University Council for East Africa, IUCEA (2014) Regional higher education qualifications gaps. Vol II.

Jacob, W. J. and Holsinger, D. B. (2009) Inequality in Education: A Critical Analysis, in Donald B. Holsinger \& W. James Jacob (Eds.) Inequality in Education: Comparative and International Perspectives (pp. 1-33). Hong Kong \& Dordrecht, Netherlands: CERC/Springer.

Kinser, K., Levy, D., Casillas, J.C.S., Bernasconi, A., Slantcheva Durst, S., Otieno, W., Lane, J., Praphamontripong, P., Zumeta, W. and LaSota, R. (2010) 'The global growth of private higher education', ASHE Higher Education Report Series, Wiley, San Francisco.

Marginson, S. (2016) The worldwide trend to high participation higher education: Dynamics of social stratification in inclusive systems. Higher Education, 72 (4), 413434. 
McCowan, T. (2016a) Universities and the post-2015 development agenda: an analytical framework. Higher Education, 72 (4), 505-525.

McCowan, T. (2016b) Three dimensions of equity of access to higher education. Compare: A Journal of Comparative and International Education 46, no. 4: 645-665.

McCowan, T., Oanda, I. and Oketch, M. (2017) Towards a National Graduate Destinations Survey in Kenya: An Exploratory Study of Three Universities. Higher Education Policy. doi: 10.1057/s41307-017-0044-x

McCowan, T., Walker, M., Fongwa, S.,Oanda, I., Sifuna, D., Adedeji, S., Oyebade, S., Ananga, E., Adzahlie-Mensah,V. and Tamanja, E. (2016) Universities, Employability and Inclusive Development: repositioning higher education in Ghana, Kenya, Nigeria and South Africa. Manchester: British Council.

McCowan, T., Ananga, E., Oanda, I., Sifuna, D., Ongwenyi, Z., Adedeji, S., Oyebade, S., Walker, M., Fongwa, S. and James, Z. (2015) Students in the driving seat: young people's views on higher education in Africa. Manchester: British Council.

Morley, L. and Lugg, R. (2009) Mapping meritocracy: Intersecting Gender, Poverty and Higher Educational Opportunity Structures. Higher Education Policy, 22 (1): 37-60.

Oanda, I. and Sifuna, D. (20016) Divergent Narratives on Graduate Employability in Kenya: Dysfunctional Institutions or Dysfunctional Labour Markets? In McCowan, T., Walker, M., Fongwa, S., Oanda, I., Sifuna, D., Adedeji, S., Oyebade, S., Ananga, E., Adzahlie-Mensah, V. and Tamanja, E., Universities, Employability and Inclusive Development: repositioning higher education in Ghana, Kenya, Nigeria and South Africa. Final research report. British Council.

Oanda, I. O. and Jowi, J. (2012) University Expansion and the Challenges to Social Development in Kenya: Dilemmas and Pitfalls. Journal of Higher Education in Africa, 10/1: 49-71.

Oanda, I. O., Chege, F. and Wesonga, D. (2008) Privatisation and Private Higher Education in Kenya: Implications for Access, Equity and Knowledge Production. Dakar: CODESRIA.

Odhiambo, G.O. (2011) Higher education quality in Kenya: a critical reflection on key challenges. Quality in Higher Education, 17, 299-315.

Odhiambo, G.O. (2013) Academic Brain Drain: Impact and Implications for Public Higher Education Quality in Kenya. Research in Comparative and International Education 8: 510-523,

Odhiambo (2014) Quality assurance for public higher education: context, strategies and challenges in Kenya. Higher Education Research \& Development, 33 (5), 978-991. 
Oketch, M. (2003) Market Model of Financing Higher Education in Sub-Saharan Africa: Examples from Kenya. Higher Education Policy, 3 (1) 313-332

Oketch, M. (2016) Financing higher education in sub-Saharan Africa: some reflections and implications for sustainable development. Higher Education 72.4: 525-539.

Otieno, W. (2010) Growth in Kenyan Private Higher Education In Kinser, K., Levy, D., Casillas, J.C.S., Bernasconi, A., Slantcheva Durst, S., Otieno, W., Lane, J., Praphamontripong, P., Zumeta, W. and LaSota, R. 'The global growth of private higher education', ASHE Higher Education Report Series, Wiley, San Francisco (pp. 51-62).

Owuor, N. A. (2012) Higher Education in Kenya: The Rising Tension between Quantity and Quality in the Post-Massification Period. Higher Education Studies, 2 (4): 126136.

Pitan, O. S. and Adedeji, S. O. (2012). 'Skills Mismatch among University Graduates in the Nigerian Labour Market'. Journal of US-China Education Review, 2, 90-98.

Republic of Kenya (2007) Kenya Vision 2030 - A Globally Competitive and Prosperous Kenya. Nairobi: Office of the Prime Minister, Ministry of State for Planning, National Development and Vision 2030.

Republic of Kenya (2013) National Manpower Survey Basic Report. Nairobi; Ministry of Labour.

Republic of Kenya (2015) Economic Survey. Nairobi: Kenya National Bureau of Statistics.

Republic of Kenya (2017) Economic Survey. Nairobi: Kenya National Bureau of Statistics.

Salmi, J. (1992). The Higher Education Crisis in Developing Countries: Issues, Problems, Constraints and Reforms. International Review of Education, 38 (1), 19-33.

Schendel, R. (2016) Constructing departmental culture to support student development: Evidence from a case study in Rwanda. Higher Education, 72 (4), 487-504.

Schweisfurth, M. (2013). Learner-centred education in international perspective: Whose pedagogy for whose development? Oxford: Routledge.

Sifuna, D. N. (1998) The governance of Kenyan public universities, Research in PostCompulsory Education, 3(2), 175-12.

Sifuna, D. N. (2010) Some reflections on the expansion and quality of higher education in public universities in Kenya. Research in Post-Compulsory Education, 15 (4), 415425.

Tam, M. (2001) Measuring Quality and Performance in Higher Education. Quality in Higher Education. 7(1), 47-54. 
Tettey, W. J. and Partnership for Higher Education in Africa (2009). Deficits in academic staff capacity in Africa and challenges of developing and retaining the next generation of academics. [Online]. Available at: http://www.foundationpartnership.org/pubs/pdf/Tettey_NGA_Indicators_Dec2009.pdf

Tilak, J.B.G. (2013), Higher Education in India: In Search of Equality, Quality and Quantity. Essays from Economic and Political Weekly, Hyderabad: Orient Blackswan.

Trow, M. (2006) Reflections on the TraNIStion from Elite to Mass to Universal Access: Forms and Phases of Higher Education in Modern Societies since WWII., in J. J. F. Forest and P. G. Altbach (eds.), International Handbook of Higher Education. Part One: Global Themes and Contemporary Challenges, Springer, Dordrecht.

UIS (UNESCO Institute for Statistics) (2016) Statistical Tables. Education: Gross Enrolment Ratio by Level of Education. Available at http://data.uis.unesco.org/index.aspx?queryid=142\&lang=en (Accessed 24/5/16)

UNESCO (2004) Education for All: The Quality Imperative (EFA Global Monitoring Report 2005). Paris: UNESCO.

UNICEF (2000) Defining Quality in Education. New York, UNICEF. Available at: http://www.unicef.org/education/files/QualityEducation.PDF (Accessed $25 / 5 / 16)$.

Unterhalter, E., Vaughan, R. and Smail, A. (2013) Secondary, Post Secondary and Higher Education in the Post-2015 discussions. London: British Council.

Wangenge-Ouma, G. (2007) Higher education marketisation and its discontents: the case of quality in Kenya. Higher Education, 56 (4): 457-471.

World Bank (2010). Financing higher education in Africa. Washington DC: The World Bank. 